7. MeGovern PG, Pankow IS, Shahar E, et al. Recent trends in aeute corenary heart disease mertality, morbidity, medical care, and risk facters. N Engl J Med 1996;334:884 90 .

8. National Genter for Health Statisties, Division of Vital Statisties. Public use data tapes for U.S. mertality, 1970 to 1995 and provisional tabulations for 1996. Hyattsville, Md.: National Center for Health Statistics, 1997. 9. National Center for Health Statisties. National hespital discharge sur rey. Vital and health statisties. Series 13. Nos. 1974 to 1998 . Washington D.G.: Government Printing Office, 1998

10. National Heart, Lung, and Bloed Institute. Merbidity and mortality 1996 chartbeok on cardioraseutar, lung, and blood diseases. Bethesda Md.: National Institutes of Health, 1996.

11. Rosamend WD, Chambless $L E$, Folsem AR, et al. Trends in the inci dence of myocardial infaretion and in mortality due to coronary heart dis ease, 1987 to 1994. N Engl J Med 1998;339:861-7.

12. Goldberg RJ, Gorak EJ, Yarzebski J, et al. A communitywide perspec tive of sex differences and temporal trends in the incidence and strvival rates after acute myocardial infaretion and out of hospital deaths caused by coronary heart disease. Arch Intern Med 1993;87:1947-53.

13. Wilsen PW, D'Agestine RB, Levy D, Belanger AM, Silbershatz $\mathrm{H}$, Kannel WB. Prediction of cerenary heart disease using risk facter categeries. Gireulation 1998:97:1837 47.

14. Hunink MG, Goldman $L$, Tostesen $A N$, et al. The recent decline in mortality from coronary heart disease, 1980-1990: the effect of secular trends in risk factors and treatment. JAMA 1997;277:535 12 .

15. Assaf AR, Lapane $K L$, MeKenny $U$, Garleten RA. Possible influence of the prospective payment system on the assignment of discharge diag noses for corenary heart disease. N Engl J Med 1993;329:931 5.

(C)1998, Massachusetts Medical Society.

\section{Chloramphenicol Resistance in Meningococci}

$\mathrm{T}$ HE familiar triad of pathogens responsible for most cases of bacterial meningitis was first shown to yield to treatment with $\beta$-lactam antibiotics and chloramphenicol over four decades ago. Chloramphenicol proved to be an effective alternative for the treatment of pneumococcal and meningococcal disease in patients who were allergic to penicillin and was particularly effective in treating meningitis caused by Haemophilus influenzae. Chloramphenicol's loss of favor began in the 1960s, when it was shown to have two distinct toxic effects on hematopoiesis: a frequently observed, dose-dependent anemia, reversible on cessation of therapy, and an irreversible, "idiosyncratic" aplastic anemia, which had an incidence of approximately 1 case per 30,000 courses of therapy, a high case fatality rate, and no correlation with the dosage or duration of treatment. ${ }^{1}$

The use of the antibiotic (apart from topical use) has become restricted to life-threatening infections for which there are no acceptable alternative treatments. In the absence of an experimental screening method to identify "safe" compounds, there has been little effort to discover an analogue that has the broad-spectrum potency of chloramphenicol but without the risk of causing aplastic anemia. Probably because of the reduction in the use of chloramphenicol, the emergence of resistance to it in developed countries has slowed. In developing countries, however, where chloramphenicol is still widely used because of its ease of administration and low cost, the appearance of novel resistant pathogens has continued.

High-level resistance to chloramphenicol is almost always due to the action of chloramphenicol acetyltransferase (CAT), which modifies the antibiotic by $\mathrm{O}$-acetylation at the 3-hydroxyl group, thereby destroying the drug's affinity for bacterial ribosomes and its ability to inhibit bacterial growth. ${ }^{2}$ The gene for the enzyme (cat) is often found as part of a mobile genetic element (a plasmid, transposon, or bacteriophage). Although the CAT family of enzymes is now widespread in chloramphenicol-resistant bacteria ${ }^{3}$ it appears to have no function apart from its ability to inactivate the antibiotic, specifically and efficiently. The origin of CAT is obscure, but it is probably related to the acetyl-transfer machinery of a multicomponent enzyme of cell metabolism namely, pyruvate dehydrogenase. ${ }^{4}$

In this issue of the Journal, Galimand et al. ${ }^{5}$ report careful studies of 12 independent isolates (all serogroup B) of chloramphenicol-resistant Neisseria meningitidis from 12 patients with serious meningococcal disease. Eleven patients were from Vietnam, where intramuscular administration of chloramphenicol is commonly used for the treatment of meningococcal meningitis; one patient was a child in France who had never been to Southeast Asia. Galimand et al. show that the cat genes that mediated the resistance were identical, or nearly so. A bigger surprise is that the gene has been described in Clostridium perfringens ${ }^{6}$ and designated catP. Finding the genetic and epidemiologic trail of the movement of a gene from anaerobic gram-positive bacilli (C. perfringens) to aerobic gram-negative cocci (N. meningitidis) is tricky, but there may be some clues.

The catP gene found in the chloramphenicolresistant isolates of $N$. meningitidis was first detected in a transposable genetic element, transposon $\mathrm{Tn} 4451$, which encodes the DNA needed for its own transfer from one bacterial chromosome (or plasmid) to another. ${ }^{7,8}$ Galimand et al. found that in each of the 12 $N$. meningitidis strains they examined, the catP insert lacked most of the flanking DNA that is essential for transposition, the chromosomal inserts were identical, and the exogenous catP was always inserted at precisely the same site.

What can one make of all of this? First, it may be useful to recall that transposons have evolved to be highly efficient "messengers," with the machinery to jump taxonomic and physiologic barriers to the chromosomes of other bacteria. Hence, as the authors propose ${ }^{5}$ there must have been one or more intermediate hosts for $\mathrm{Tn} 445 \mathrm{I}$ before the truncated form became associated with the chromosomes of chloramphenicol-resistant meningococci. In other words, Tn 4451 is promiscuous. Galimand et al. ${ }^{5}$ also 
show that the 12 independent isolates of N. meningitidis that carried catP were phenotypically distinct meningococcal variants and were not clonal. Each must have arisen independently. Hence, in this intriguing puzzle that remains to be solved, the very same truncated segment of Tn 4451 appeared in 12 different strains of $N$. meningitidis, inserted at precisely the same site of the meningococcal chromosomes.

As Galimand et al. point out ${ }^{5}$ meningococci are highly competent in the process of genetic transfer by transformation, which involves the uptake of DNA but does not require cell-to-cell contact. Transposons move about, often borne by plasmids. At some point, there may have been an abortive transposition of Tn 4451 into a meningococcus, with the extensive deletions from $\mathrm{Tn} 4451$ due to faulty excision (or insertion) leaving catP immobile and effectively "beached" in N. meningitidis. The subsequent transfer of the Tn4451-derived DNA (containing catP) probably occurred by transformation, with precise recombination between incoming and resident meningococcal DNA, followed by selection for a chloramphenicol-resistant transformant.

At the practical level, there is now a strong possibility that the CATP phenotype of chloramphenicol resistance will become more prevalent in clinical isolates of $N$. meningitidis, at least in countries where the antibiotic is commonly used. There may be less immediate cause for concern in the parts of the world where chloramphenicol is no longer widely used. In these countries, however, chloramphenicol is still used for the treatment of acute bacterial meningitis. Because the incidence of resistance to the drug by Streptococcus pneumoniae and H. influenzae is generally low, it will continue to prove useful in special circumstances. Chloramphenicol enters the cerebrospinal fluid with ease, even in the absence of meningeal inflammation, ${ }^{9}$ and appears to have bactericidal activity against meningococci, pneumococci, and H. influenzae..$^{10}$

Analogues of chloramphenicol have been developed that lack the aromatic $\mathrm{NO}_{2}$ group, which is thought to cause irreversible marrow aplasia, and that also cannot be inactivated by CAT. Although the clinical efficacy of such compounds has not been evaluated, they are effective in vitro against most bacteria that are resistant to chloramphenicol because of the presence of CAT. ${ }^{11}$ Nonetheless, because there is as yet no way to monitor the potential for irreversible bone marrow toxicity, it is unlikely that such compounds will become available for the treatment of chloramphenicol-resistant infections in general - and meningococcal disease in particular.

WiLliam V. SHAW, M.D.

University of Leicester School of Medicine Leicester LE1 9HN, United Kingdom

\section{REFERENCES}

1. Yunis AA. Chloramphenicol: relation of structure to activity and toxicity. Annu Rev Pharmacol Toxicol 1988;28:83-100.

2. Shaw WV. The enzymatic acetylation of chloramphenicol by extracts of

R factor-resistant Escherichia coli. J Biol Chem 1967;242:687-93.

3. Shaw WV, Leslie AG. Chloramphenicol acetyltransferase. Annu Rev Biophys Biophys Chem 1991;20:363-86.

4. Mattevi A, Obmolova G, Kalk KH, Teplyakov A, Hol WG. Crystallographic analysis of substrate binding and catalysis in dihydrolipoyl

transacetylase (E2p). Biochemistry 1993;32:3887-901.

5. Galimand M, Gerbaud G, Guibourdenche M, Riou J-Y, Courvalin P.

High-level chloramphenicol resistance in Neisseria meningitidis. N Engl J

Med 1998;339:868-74.

6. Steffen C, Matzura H. Nucleotide sequence analysis and expression studies of a chloramphenicol-acetyltransferase-coding gene from Clostridium perfringens. Gene 1989;75:349-54.

7. Bannam TL, Crellin PK, Rood JI. Molecular genetics of the chloramphenicol-resistance transposon Tn4451 from Clostridium perfringens: the TnpX site-specific recombinase excises a circular transposon molecule. Mol Microbiol 1995;16:535-51.

8. Abraham LJ, Rood JI. The Clostridium perfringens chloramphenicol resistance transposon Tn4451 excises precisely in Escherichia coli. Plasmid 1988;19:164-8.

9. Friedman CA, Lovejoy FC, Smith AL. Chloramphenicol disposition in infants and children. J Pediatr 1979;95:1071-7.

10. Rahal JJ Jr, Simberkoff MS. Bactericidal and bacteriostatic action of chloramphenicol against meningeal pathogens. Antimicrob Agents

Chemother 1979;16:13-8.

11. Syriopoulou VP, Harding AL, Goldmann DA, Smith AL. In vitro an tibacterial activity of fluorinated analogs of chloramphenicol and thiamphenicol. Antimicrob Agents Chemother 1981;19:294-7.

(C)1998, Massachusetts Medical Society.

\section{Depression IN THE ElperLy Falls and Pitfalis}

$\mathrm{C}$ OMAMITTING a patient to a course of drug therapy, particularly a long term one, often represents a delicate balancing act in which the physi cian must juggle estimates of benefit and risk and increasingly, must factor in costs as well. As with se many things in medicine, the stakes are dramatically higher for the elderly. Older persens have the great est burden of disease that could benefit from thera peutic or preventive therapy but are also more likely to have side effects from such therapy. These consid erations are magnified even further for frail older patients with medically complex conditions who live in mursing homes. ${ }^{+}$Often they receive more medica tions and less attention from physicians than their eounterparts residing in the community. Even theugh such older patients are the very people for whom we need the most data with respect to the safety and ef ficacy of medications, they are the ones about whom we know the least, and they are rarely included in drug trials. In this issue of the Journal, Thapa and eolleagues ${ }^{2}$ present the results of an ambitious ret rospective study designed to shed light on a partic ularly tough question: What is the risk of falls asseciated with the use of antidepressants by patients in nursing homes?

Why resert to an observational approach to this 